\title{
A comprehensive analysis of the expression and regulation network of lymphocyte-specific protein tyrosine kinase in breast cancer
}

\author{
Yuhua Meng, Ting Huang, Xuanzhao Chen, Yuanzhi Lu \\ Pathological Diagnosis and Research Center, Affiliated Hospital of Guangdong Medical University, Zhanjiang, China \\ Contributions: (I) Conception and design: Y Meng; (II) Administrative support: Y Lu; (III) Provision of study materials or patients: Y Meng, T Huang; \\ (IV) Collection and assembly of data: Y Meng, T Huang; (V) Data analysis and interpretation: Y Meng, X Chen; (VI) Manuscript writing: All \\ authors; (VII) Final approval of manuscript: All authors. \\ Correspondence to: Yuan-Zhi Lu. Pathological Diagnosis and Research Center, Affiliated Hospital of Guangdong Medical University, Zhanjiang \\ 524023, China. Email: Yuanzhi.lu@jun.edu.cn.
}

Background: Lymphocyte-specific protein tyrosine kinase (LCK), an encoded Src family protein tyrosine kinase, performs a pivotal molecular signaling role in the selection and maturation processes during T-cell development. Although aberrant LCK expression is known to have a significant association with carcinogenesis, the underlying role of $L C K$ in breast cancer (BC) is still obscure.

Methods: An analysis of the levels of $L C K$ mRNA expression in $\mathrm{BC}$ was performed, and the value of $L C K$ expression for predicting the prognosis of patients with $\mathrm{BC}$ was studied using various online data resources, which included Oncomine, Gene Expression Profiling Interactive Analysis (GEPIA), and UALCAN. The web-based NetworkAnalyst tool was utilized to investigate the functional network of differentially expressed $L C K$. LinkedOmics was employed to identify the genes with which $L C K$ has correlations in $\mathrm{BC}$, together with the kinases, microRNAs, and transcription factors (TFs) potentially targeted by $L C K$ in BC. The expression levels of LCK and its significantly correlated genes in BC were investigated with the Human Protein Atlas (HPA).

Results: We observed a significant difference in the level of LCK mRNA expression between BC patients and healthy individuals, and a higher LCK expression was associated with poor overall survival (OS). The functional enrichment results revealed that the differential expression of $L C K$ was mainly involved in the regulation of immune response and inflammatory response in BC. The expression of significantly related genes, such as inducible T-cell kinase (ITK), CD5, CD96, CD247, SH2 domain containing 1A (SH2D1A), phosphatidylinositol-4,5-bisphosphate 3-kinase (PIK3CD), Src-like-adaptor 2 (SLA2), and interleukin 2 receptor (IL2RG), was associated with poor OS in patients with BC. Regulatory network analysis found that LCK regulated immune cells, cancer progression, apoptosis, and cell cycle signal transduction through cancerrelated kinases (ITK and MAPK3), miRNAs (miR-345 and miR-524), and TFs (AP1, SRF, and E2F1).

Conclusions: This study presents new perspectives on the differential expression and prognostic value of LCK in BC. Our observations will provide a basis for further study on the oncogenic and regulatory roles of LCK in BC.

Keywords: Breast cancer (BC); bioinformatics analysis; functional network; lymphocyte-specific protein tyrosine kinase (LCK); prognosis

Submitted Jan 25, 2021. Accepted for publication Mar 18, 2021.

doi: $10.21037 /$ tcr-21-328

View this article at: http://dx.doi.org/10.21037/tcr-21-328 


\section{Introduction}

Breast cancer (BC) was the one of the commonest cancer types for China (1). Each year, almost 1.7 million cases of $\mathrm{BC}$ are diagnosed, and 500,000 people die due to this disease (2). Approximately 1 in every 8 to 10 women will suffer from BC in their lifetime (3). With the development of advanced diagnostic methods and more effective therapies in the past few years, mortality among patients with BC has decreased. In 2016, BC was responsible for $8 \%$ of all deaths in the European Union (4), and it is still the biggest contributor to cancer-related death around the world. Therefore, it is crucial to find a more sensitive and effective biomarker for the diagnosis of BC, as well as potential therapeutic targets.

Lymphocyte-specific protein tyrosine kinase (LCK) was first identified to be part of the Src protein tyrosine kinase family in the 1980s (5). LCK is composed of N-terminal site (Src-homology 4, SH4 domain), a unique region, a SH3 and $\mathrm{SH} 2$ domain, a catalytic domain, and a short C-terminal tail (6). Later research demonstrated LCK to be a regulator of T-cell receptor (TCR) signaling, and T-cell development and homeostasis. LCK also acts as an important regulator of chimeric antigen receptor (CAR)-engineered $\mathrm{T}$ cells (7). Further studies showed that LCK is differentially expressed in various types of cancers and that the biological function of LCK differs depending on the cancer. Cancers in which LCK expression has been detected include BC, lung cancer, colon cancer, cholangiocarcinoma, and glioma (8-12). In cholangiocarcinoma, high LCK expression is considered to be a risk factor for tumor recurrence (8). Previous studies have also reported that LCK may be an important regulator of cancer stem cells (CSC) (13), which contribute to tumor drug resistance and recurrence. In another study, LCK is a potential therapeutic gene for acute myeloid leukemia (AML) (14). Compared to Bai et al. study, we not only analyzed the LCK gene but also explored the significant correlated-genes and significant regulators such as PIK3CD, SLA2, IL2RG, ITK, MAPK3, miR-345 and miR-524 of LCK (15). Based on the evidence described above, it can be speculated that LCK may be a diagnostic biomarker and a potential therapeutic target for patients with cancer. However, a lack of clarity still surrounds the role LCK plays in BC. Here, we studied the expression levels and prognostic value of LCK in patients with BC using bioinformatics tools. We mainly used The Cancer Genome Atlas (TCGA) data to perform this study, TGCA is a public funded project that aims to catalogue and discover major cancer-causing genomic alterations to create a comprehensive "atlas" of cancer genomic profiles (16).

We present the following article in accordance with the MDAR reporting checklist (available at http://dx.doi. org/10.21037/tcr-21-328).

\section{Methods}

UALCAN (http://ualcan.path.uab.edu) is an online portal which allows users to interactively and straightforwardly conduct comprehensive analysis of gene expression data from The Cancer Genome Atlas (TCGA) (17). Using UALCAN, we examined the expression level of LCK in BC according to different clinicopathological features, such as age, sex, histological subtype, co-mutation status, and stage.

\section{Gene Expression Profiling Interactive Analysis (GEPIA) analysis}

GEPIA (http://gepia.cancer-pku.cn) is an online server delivering functions that can be customized by the user to rapidly analyze data from TCGA and Genotype-Tissue Expression (GTEx) projects (18). To study the prognostic roles of LCK and the genes with which it is significantly correlated in BC, we constructed survival curves using GEPIA. Independent-samples $t$-test was employed for the prognostic analysis, with $\mathrm{P}<0.05$ set as the threshold for significance.

\section{PrognoScan analysis}

PrognoScan is a database that can be used to investigate the associations between defined genes and prognosis for multiple cancers (https://www.abren.net/PrognoScan/) (19). We validated the prognostic role of $\mathrm{LCK}$ in $\mathrm{BC}$ via PrognoScan with data derived from the Gene Expression Omnibus (GEO).

\section{GeneMANIA analysis}

GeneMANIA (https://genemania.org) is website that can be used to construct protein-protein interaction (PPI) networks (20). We use GeneMANIA to predict the function of the LCK gene and visualize the gene network.

\section{LinkedOmics analysis}

LinkedOmics (http://www.linkedomics.org) contains 
multi-omics and clinical data of 11,158 individuals with 32 different cancers from TCGA. This web-based resource allows researchers to access multi-omics data for analysis and comparison within and among cancer types (21). We found the genes with significant correlations with LCK (Pearson's correlation $\geq 0.6$ ) in the LinkedOmics dataset and constructed a heatmap of the top 50 correlated genes. Further, the differentially expressed genes within the TCGA BC cohort were analyzed via the "LinkFinder" module. The LinkedOmics database was also used to analyze the possible kinase targets, miRNA target, and transcription factor (TF) targets of LCK in BC.

\section{TIMER analysis}

The TIMER (https://cistrome.shinyapps.io/timer) web server can be used to analyze immune cell infiltration comprehensively and systematically in a wide variety of tumors (22). In our study, the TIMER database was utilized for the analysis of immune cell infiltration in BC, and to examine the relationship of immune infiltration with prognosis in patients with BC.

\section{Human Protein Atlas (HPA) analysis}

The HPA has the aim of mapping every protein found in the cells, tissues, and organs of humans through the use of integrated omics technologies (http://www.proteinatlas. org) (23). Differences in the expression level of LCK in tumor and normal tissue samples were examined using the HPA.

This study was approved by the Academic Committee of Guangdong Medical University and conducted according to the principles of the Helsinki Declaration (as revised in 2013).

\section{Statistical analysis}

The gene expression levels thresholds of I log2 fold change | $>1.0$ and false discovery rate $(\mathrm{FDR}<0.05), \mathrm{P}$ value $<0.05$ seemed as significant difference, the survival analysis $\mathrm{P}$ value $<0.05$ was seemed as the significant influence prognosis, and the spearman correlated value $>0.6$ seemed significantly correlated.

\section{Results}

\section{Expression levels of the LCK gene in patients with BC}

To examine the relationship between $L C K$ gene expression and BC, UALCAN was used to analyze the level of $L C K$ mRNA in BC and normal tissue samples (Figure 1). Significant upregulation of $L C K$ mRNA was observed in patients with BC. $L C K$ expression was found to differ between normal and tumor tissues when data were analyzed according to BC stage, race, sex, age, main subtypes, major subclasses with triple-negative BC, menopausal status, histological subtype, nodal metastasis status, and TP53 mutation status. To summarize, compared to normal samples, BC samples showed a significant increase in the level of $L C K$ gene expression.

\section{The relationship of $L C K$ with patient prognosis in $B C$}

To determine whether the $L C K$ gene has an influence on survival in BC, we next studied the relationship of LCK expression with the prognostic outcomes of patients with BC using the PrognoScan and GEPIA databases. Data from both databases showed that the expression of LCK significantly impacted the overall survival (OS) of patients with BC. Analysis using PrognoScan revealed an association between a high expression of LCK and a good prognostic outcome $(\mathrm{P}=0.012)$ (Figure $2 A)$. Similarly, results were observed with GEPIA, which revealed a marginal association between a high level of LCK and poor OS $(\mathrm{P}=0.041)$ (Figure 2B,C).

\section{Correlated significant genes of $L C K$ and their role in $B C$}

We continued our investigation of the role potentially played by $L C K$ in $\mathrm{BC}$ by analyzing the mRNA sequencing data of 526 patients with BC from TCGA with the LinkFinder module in LinkedOmics. A volcano plot was generated, which showed significantly positive correlations of LCK with CD5 and CD247, with a false discovery rate (FDR) of $<0.01$. Heatmaps in Figure $3 A, B, C$ show the top 50 most significant genes with a positive or negative association with LCK. We found that CD5 (Spearman correlation =9.166e-01, P=2.249e-149), CD96 (Spearman correlation $=9.074 \mathrm{e}-01, \mathrm{P}=2.325 \mathrm{e}-141), \mathrm{CD} 247$ (Spearman correlation $=9.190 \mathrm{e}-01, \mathrm{P}=1.124 \mathrm{e}-151)$, IL2RG (Spearman correlation $=8.715 \mathrm{e}-01, \mathrm{P}=1.583 \mathrm{e}-116)$, ITK $($ Spearman correlation $=8.860 \mathrm{e}-01, \mathrm{P}=1.547 \mathrm{e}-125)$, PDCD1 (Spearman correlation $=8.594 \mathrm{e}-01, \mathrm{P}=8.146 \mathrm{e}-110)$, PIK3CD (Spearman correlation $=7.790 \mathrm{e}-01, \mathrm{P}=5.088 \mathrm{e}-77$ ), SH2D1A $($ Spearman correlation $=9.079 \mathrm{e}-01, \mathrm{P}=8.332 \mathrm{e}-142)$, and SLA2 (Spearman correlation $=8.677 \mathrm{e}-01, \mathrm{P}=2.359 \mathrm{e}-114$ ) were strongly associated with LCK in BC (Figure 4). 


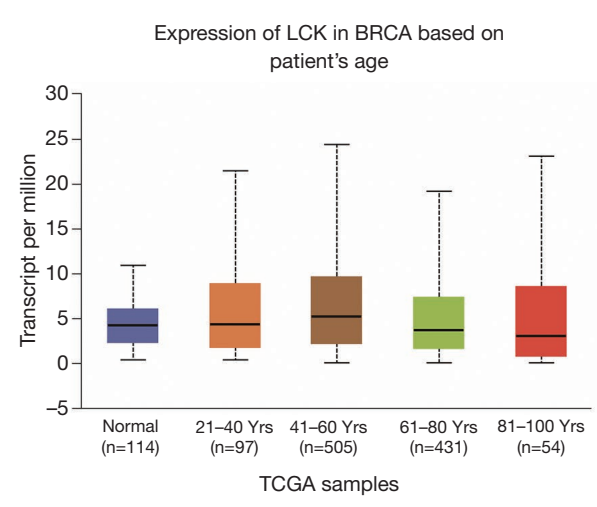

Expression of LCK in BRCA based on individual cancer stages

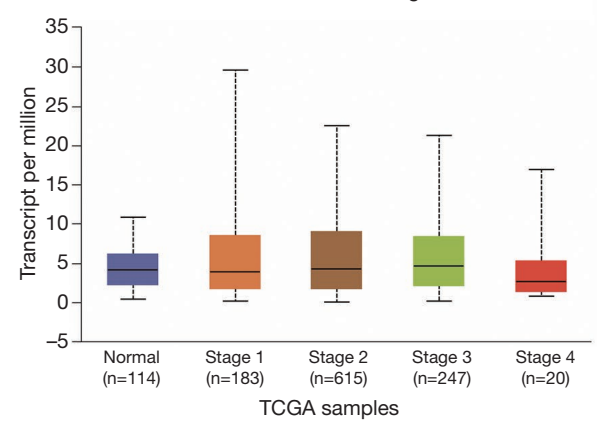

Express ion of LCK in BRCA based on patient's race

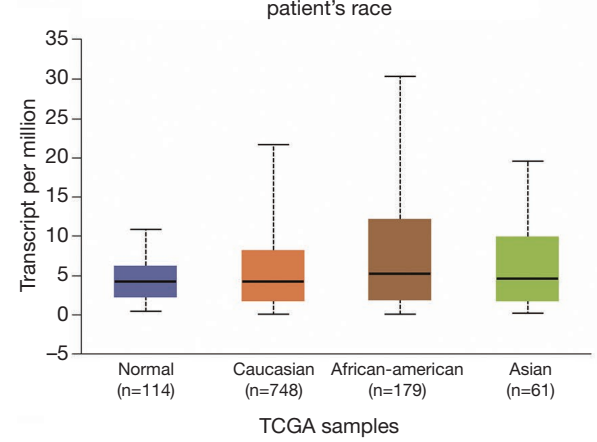

Express ion of LCK in BRCA based on breast cancer subclasses

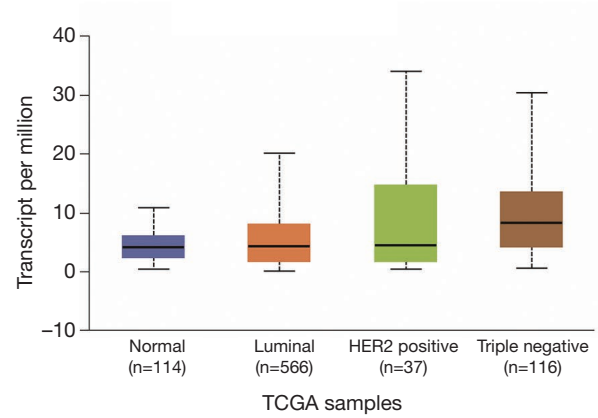

Expression of LCK in BRCA based on patient's gender

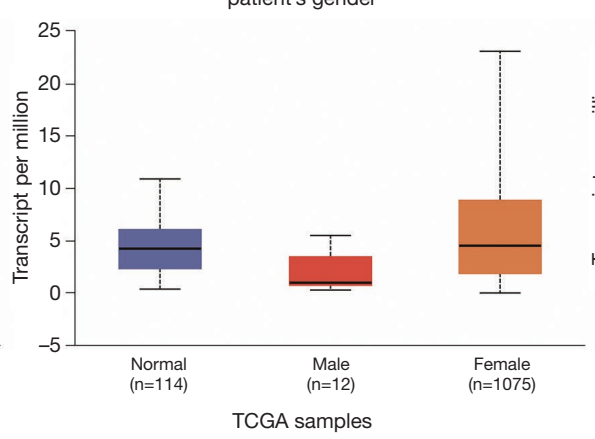

Expression of LCK in BRCA based on Menopause status

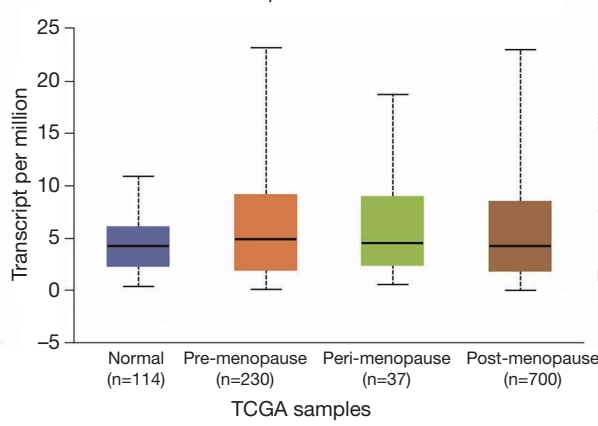

Expression of LCK in BRCA based on sample types

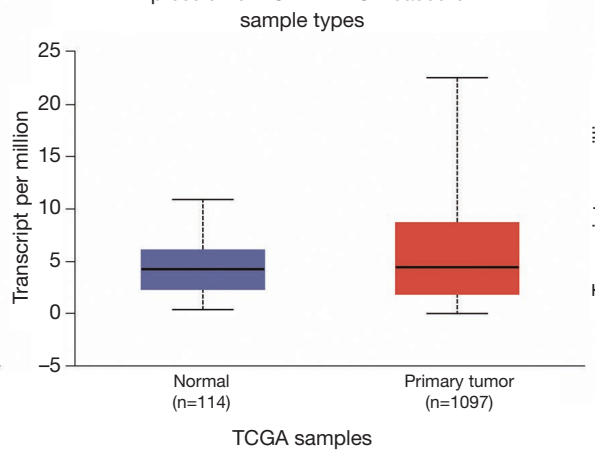

Expression of LCK in BRCA based on TP53 mutation status

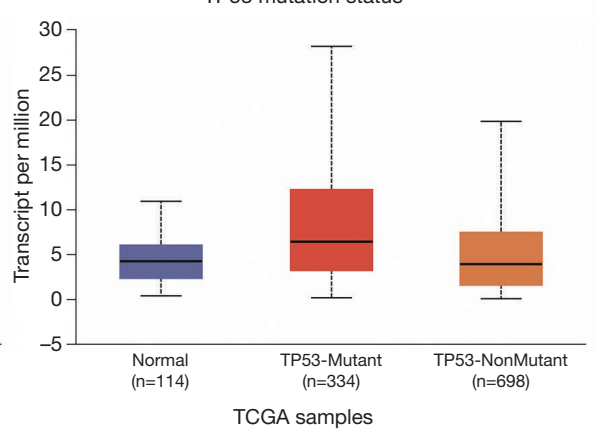

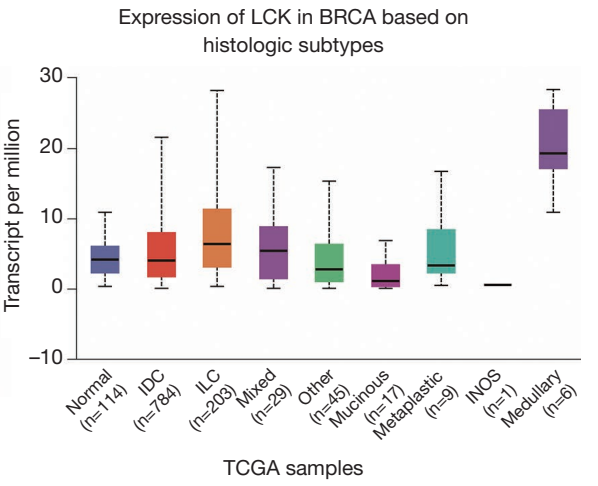

Expression of LCK in BRCA based on nodal metastasis status

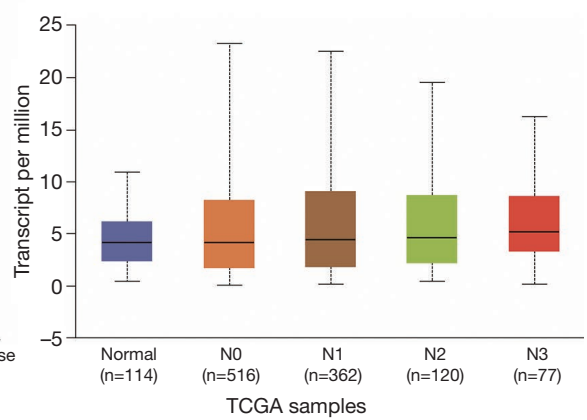

Expression of LCK in BRCA based on major subclasses (with TNBC types)

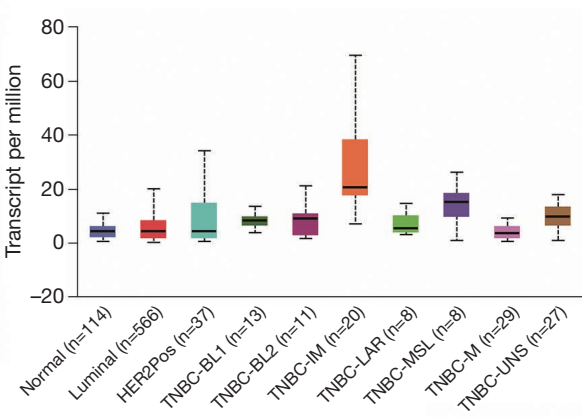

TCGA samples

Figure 1 The expression levels of LCK in breast cancer based on different clinical features. LCK, lymphocyte-specific protein tyrosine kinase. 
A

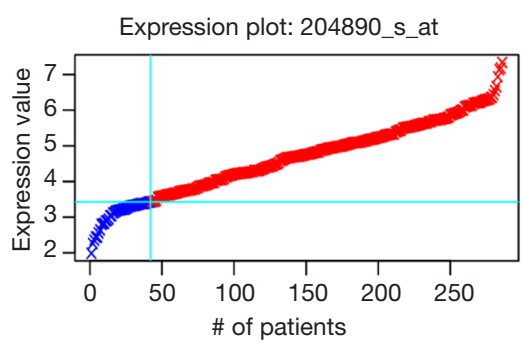

B

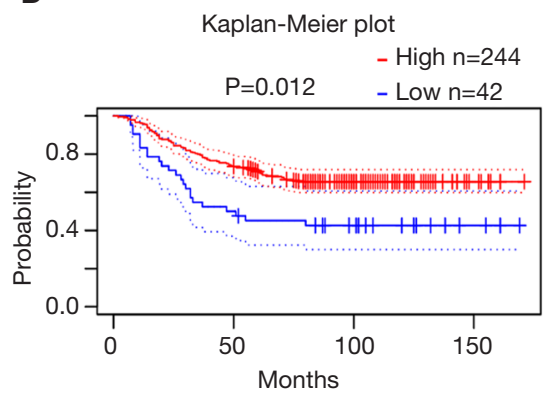

C

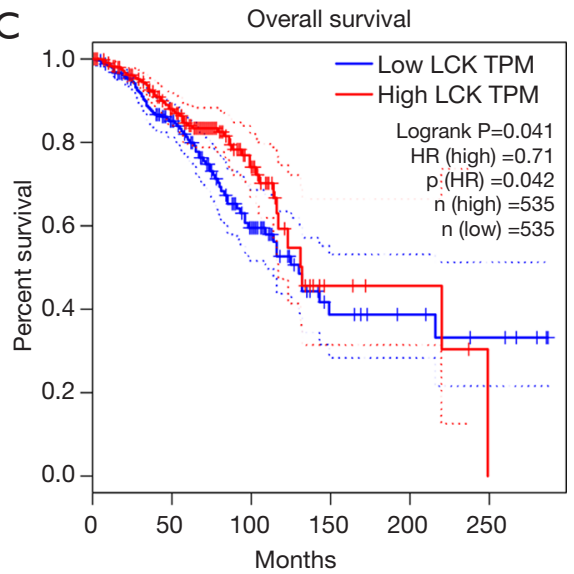

Figure 2 The LCK expression levels and its roles in breast cancer. (A) The LCK expression levels in breast cancer. (B,C) The relationship between LCK expression level and prognostic role for breast cancer. LCK, lymphocyte-specific protein tyrosine kinase.

Next, GEPIA was used to evaluate the prognostic value of the genes positively related to LCK in BC. CD5 ( $\mathrm{P}=0.0037)$, CD96 ( $\mathrm{P}=0.0036), \mathrm{CD} 247(\mathrm{P}=0.0058)$, IL2RG ( $\mathrm{P}=0.0085)$, ITK $(\mathrm{P}=0.0019)$, $\mathrm{PDCD} 1(\mathrm{P}=0.0095)$, PIK3CD $(\mathrm{P}=0.022), \mathrm{SH} 2 \mathrm{D} 1 \mathrm{~A}(\mathrm{P}=0.002)$, and SLA2 $(\mathrm{P}=0.025)$ showed significant associations with poor OS in BCs with a high transcriptional level of LCK (Figure 5).

\section{Association of LCK expression with immune cell infiltration and prognosis}

We further analyzed the association of LCK expression with immune cell infiltration and prognosis in BC using the TIMER database. The following associations were identified: In BCs, tumor purity $(\mathrm{P}=8.62 \mathrm{e}-71)$, B cells $(\mathrm{P}=2.08 \mathrm{e}-77), \mathrm{CD} 8+\mathrm{T}$ cells $(\mathrm{P}=5.65 \mathrm{e}-73), \mathrm{CD} 4+\mathrm{T}$ cells $(\mathrm{P}=3.77 \mathrm{e}-145)$, neutrophils $(\mathrm{P}=5.43 \mathrm{e}-104)$, and dendritic cells $(\mathrm{P}=3.09 \mathrm{e}-148)$; in basal-like $\mathrm{BCs}$, tumor purity $(\mathrm{P}=3.93 \mathrm{e}-14), \mathrm{B}$ Cells $(\mathrm{P}=1.75 \mathrm{e}-15), \mathrm{CD} 4+\mathrm{T}$ cells $(\mathrm{P}=3.25 \mathrm{e}-11)$, neutrophils $(\mathrm{P}=1.57 \mathrm{e}-10)$, and dendritic cells $(\mathrm{P}=3.36 \mathrm{e}-14)$; in human epidermal growth factor receptor (HER2)-positive $\mathrm{BCs}$, tumor purity $(\mathrm{P}=1.17 \mathrm{e}-05)$, CD8+ T cells $(\mathrm{P}=7.08 \mathrm{e}-13), \mathrm{CD} 4+\mathrm{T}$ cells $(\mathrm{P}=1.39 \mathrm{e}-11)$, neutrophils $(\mathrm{P}=1.35 \mathrm{e}-08)$, and dendritic cells $(\mathrm{P}=1.60 \mathrm{e}-10)$; and in luminal BCs, B cells $(\mathrm{P}=4.36 \mathrm{e}-39), \mathrm{CD} 8+\mathrm{T}$ Cells $(\mathrm{P}=1.22 \mathrm{e}-67), \mathrm{CD} 4+\mathrm{T}$ Cells $(\mathrm{P}=3.89 \mathrm{e}-85)$, neutrophils $(\mathrm{P}=3.05 \mathrm{e}-57)$, and dendritic cells $(\mathrm{P}=1.57 \mathrm{e}-82)$; all partial cord $>0.5$ or $<-0.5$ show in Figure 6. LCK was statistically significantly associated with OS in patients with luminal $\mathrm{BCs}(\mathrm{P}=0.019)$. In the subgroup analysis, B cells were found to be statistically significant for all $\mathrm{BCs}(\mathrm{P}=0.046)$ and $\mathrm{BCs}$ HER2 ( $\mathrm{P}=0.017$ ), with patients with a high expression of LCK having worse OS than patients with a low expression (Figure 7).

\section{Functional enrichment analysis of LCK}

Gene Ontology (GO) and Kyoto Encyclopedia of Genes and Genomes (KEGG) functional enrichment analyses of LCK were performed, and the results are shown in Figure 8. LCK was found to be localized in the plasma membrane and pericentrosomal vesicles, and to bind to cell surface receptors, including $\mathrm{CD} 4, \mathrm{CD} 8$, and other signaling molecules. Multiple alternatively spliced variants encoding the same protein have been described. LCK was shown to be mainly involved in lymphocyte-mediated immunity, activation of natural killer cells, regulation of leukocyte activation, and regulation of viral defense.

\section{Kinase and TF targets of LCK}

The focus of our analysis next shifted to the kinases, miRNAs, and TFs potentially targeted by LCK in the LinkedOmics database. The most significant kinase targets of LCK were found to be ITK, MAPK3, HCK protooncogene (HCK), and protein kinase $\mathrm{C}$ theta (PRKCQ) (Table 1). The miRNA targets of LCK are shown in Table 2. We identified (AGTCAGC) miR-345, (CTTTGTA) miR524, (CAGCCTC) miR-485-5P, (TTTGCAG) miR518A-2, (AGGTGCA) miR-500, and (AGCATTA) miR- 

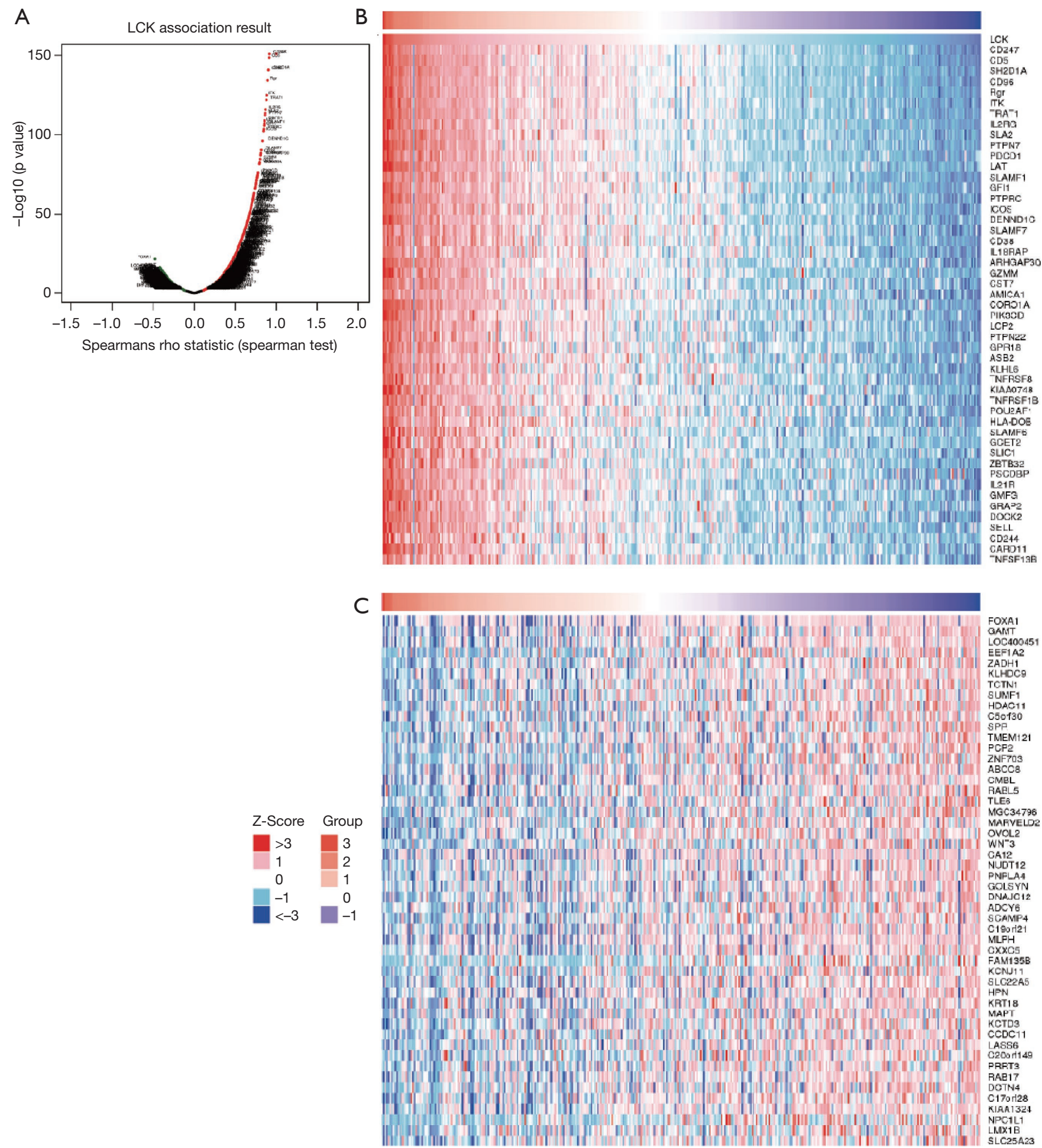

Figure 3 Differentially expressed genes correlated with differentially expressed LCK in breast cancer (LinkedOmics). (A,B,C) Volcano plots and heat maps indicating genes positively and negatively genes correlated with LCK in breast cancer, respectively (top 50). Red suggests positively correlated genes, and green suggests negatively correlated genes. LCK, lymphocyte-specific protein tyrosine kinase. 


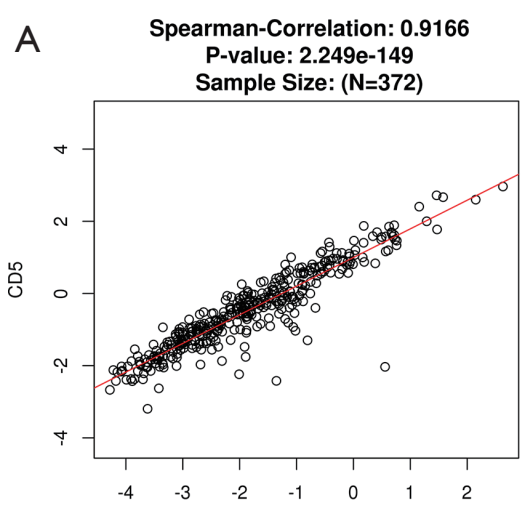

LCK
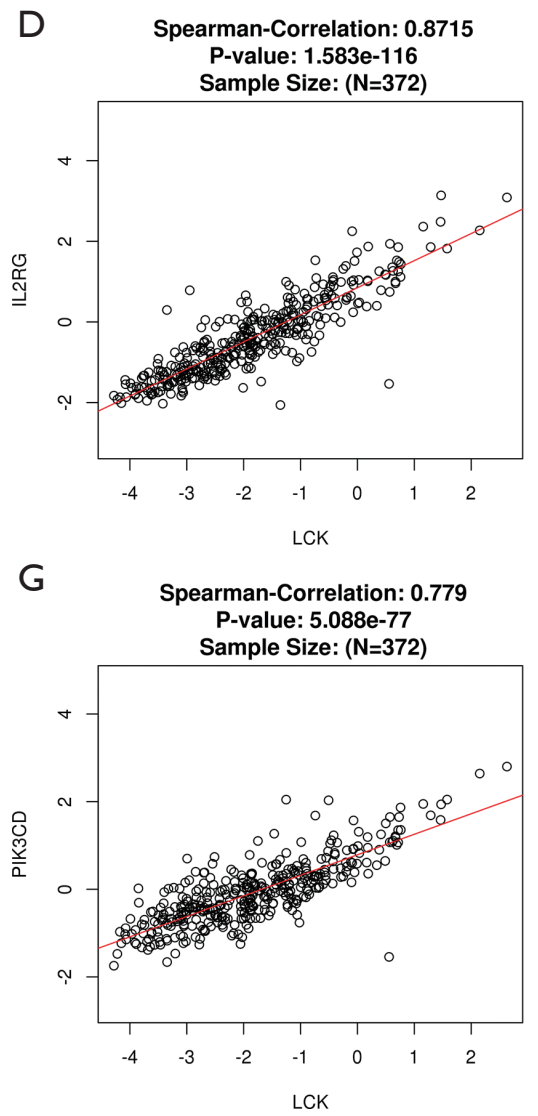

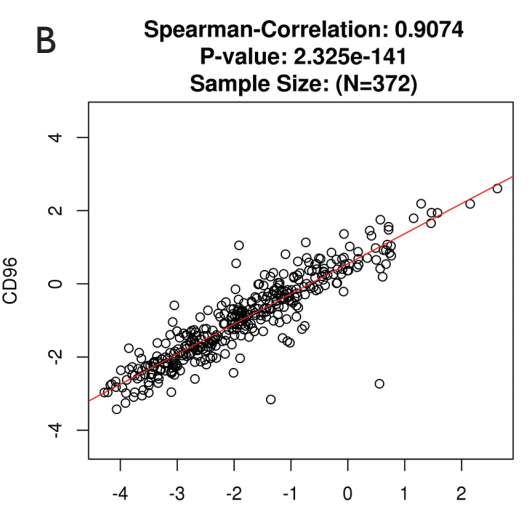

LCK
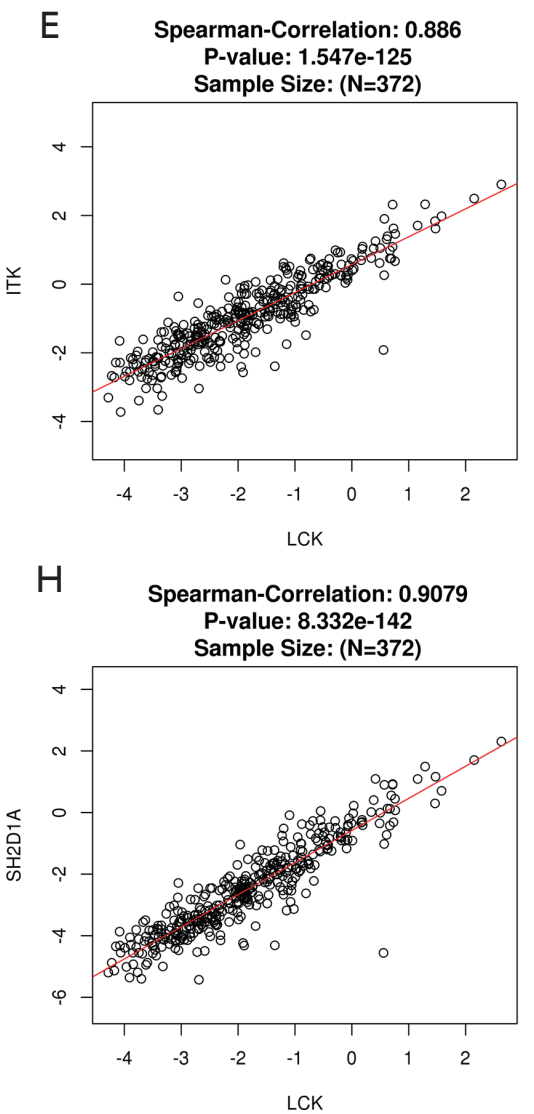

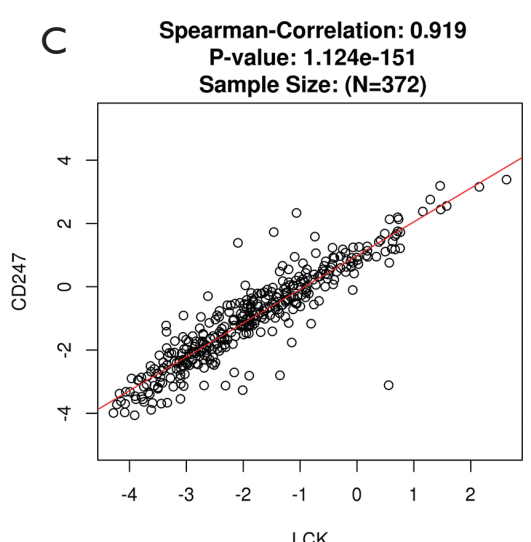

LCK
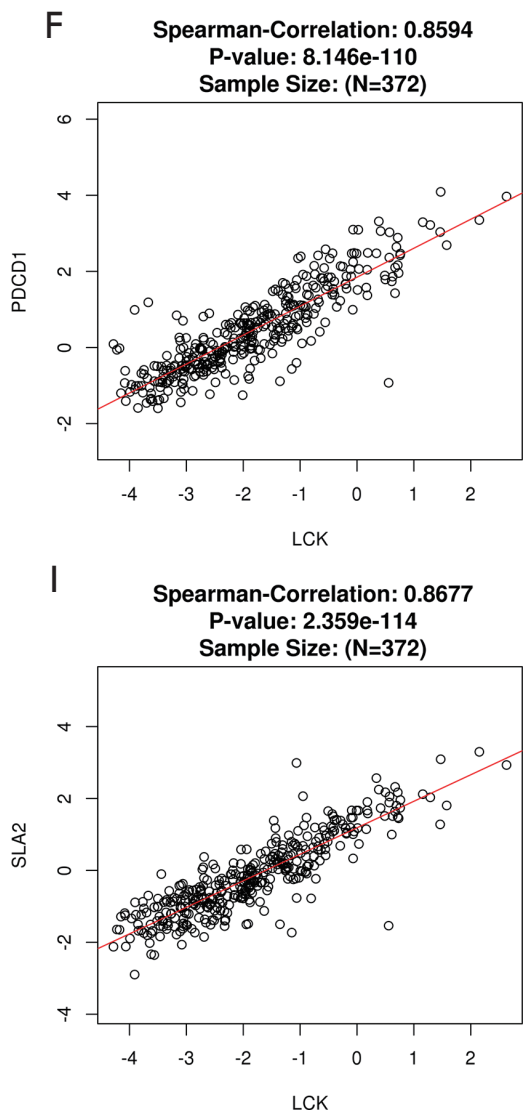

Figure 4 Genes significantly related to LCK in BC via LinkedOmics. (A) The scatter plots show Pearson's correlation of LCK expression with expression of CD5. (B) The scatter plots show Pearson's correlation of LCK expression with expression of CD96. (C) The scatter plots show Pearson's correlation of LCK expression with expression of CD247. (D) The scatter plots show Pearson's correlation of LCK expression with expression of IL2RG. (E) The scatter plots show Pearson's correlation of GPX-8 expression with the expression of ITK. (F) The scatter plots show Pearson's correlation of LCK expression with the expression of PDCD1. (G) The scatter plots show Pearson's correlation of LCK expression with the expression of PIK3CD. (H) The scatter plots show Pearson's correlation of LCK expression with the expression of SH2D1A. (I) The scatter plots show Pearson's correlation of LCK expression with the expression of SLA2. LCK, lymphocytespecific protein tyrosine kinase; BC, breast cancer. LCK, lymphocyte-specific protein tyrosine kinase; CD5, T-cell surface glycoprotein CD5; CD96, CD96 antigen; CD247, T-cell surface glycoprotein CD3 zeta chain; IL2RG, interleukin 2 receptor subunit gamma; ITK, tyrosine-protein kinase ITK; programmed cell death protein 1; PIK3CD, phosphoinositide-3-kinase; SH2D1A, SH2 domain-containing protein 1A; SLA2, Src-like adapter protein-2. 

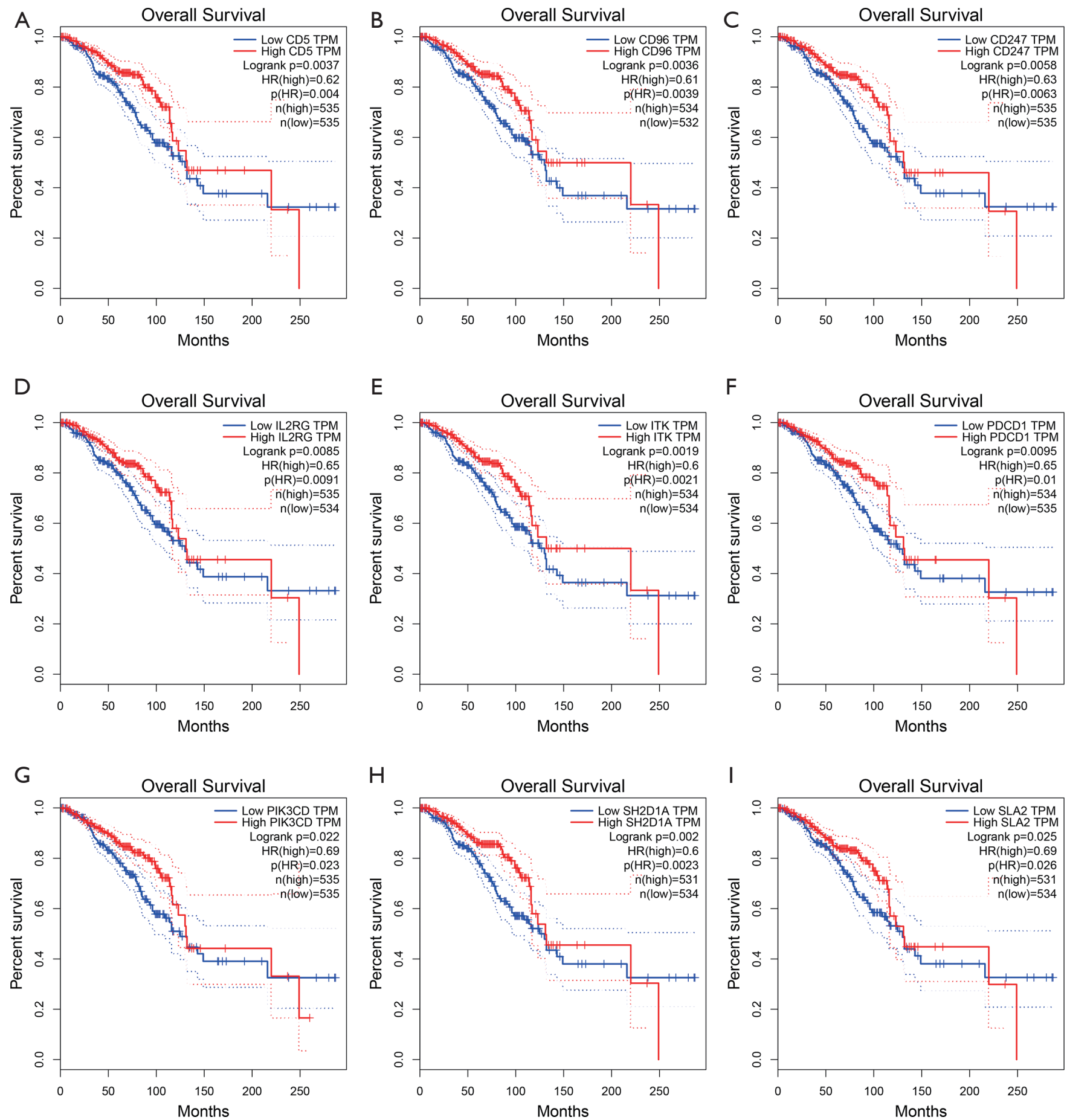

Figure 5 Prognostic analysis of genes correlated with LCK in patients with breast cancer (GEPIA). (A) The overall survival curves of CD5. (B) The overall survival curves of CD96. (C) The overall survival curves of CD247. (D) The overall survival curves of IL2RG. (E) The overall survival curves of ITK. (F) The overall survival curves of PDCD1. (G) The overall survival curves of PIK3CD. (H) The overall survival curves of SH2D1A. (I) The overall survival curves of SLA2. LCK, lymphocyte-specific protein tyrosine kinase; CD5, T-cell surface glycoprotein CD5; CD96, CD96 antigen; CD247, T-cell surface glycoprotein CD3 zeta chain; IL2RG, interleukin 2 receptor subunit gamma; ITK, tyrosine-protein kinase ITK; programmed cell death protein 1; PIK3CD, phosphoinositide-3-kinase; SH2D1A, SH2 domaincontaining protein 1A; SLA2, Src-like adapter protein-2. 


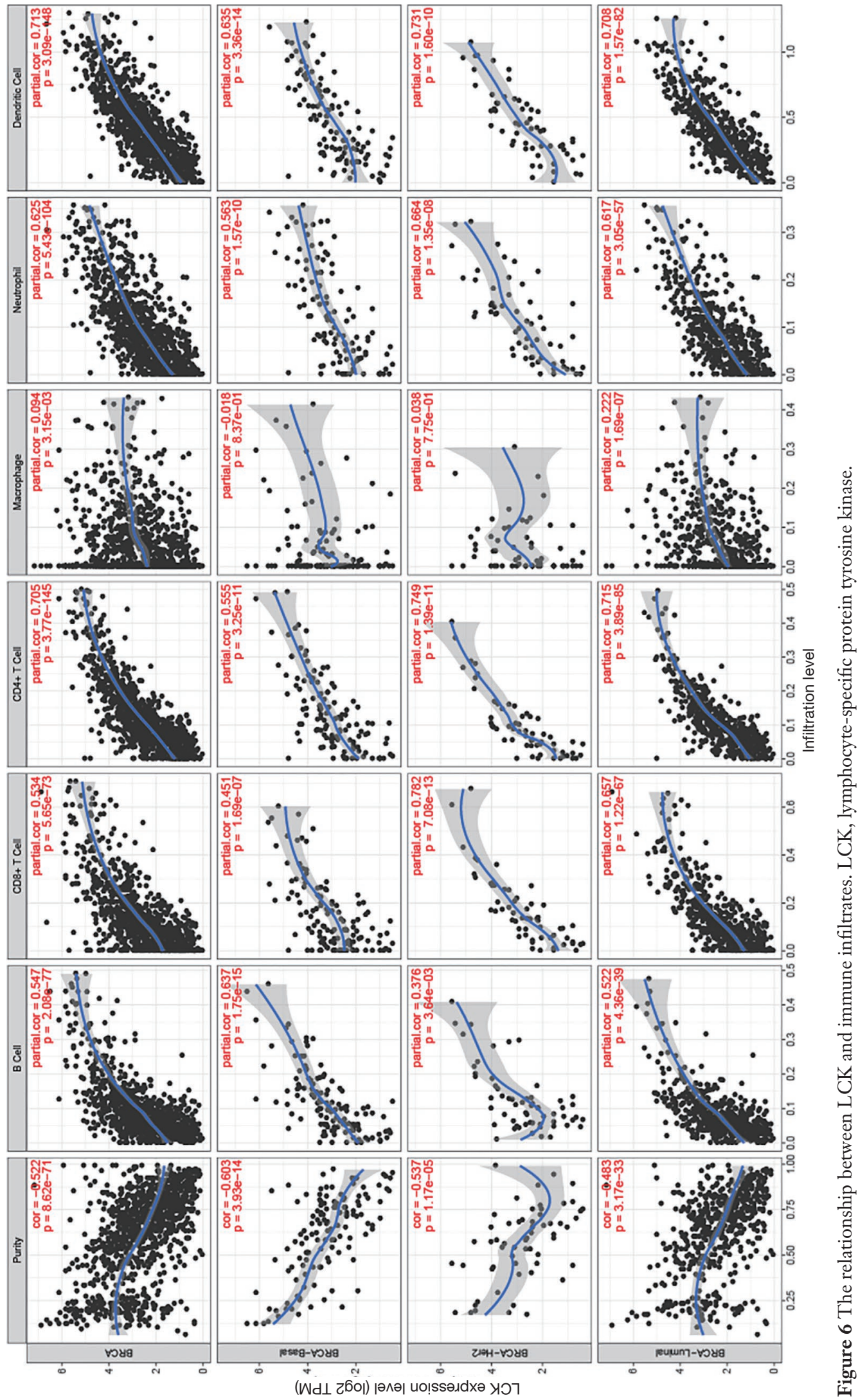




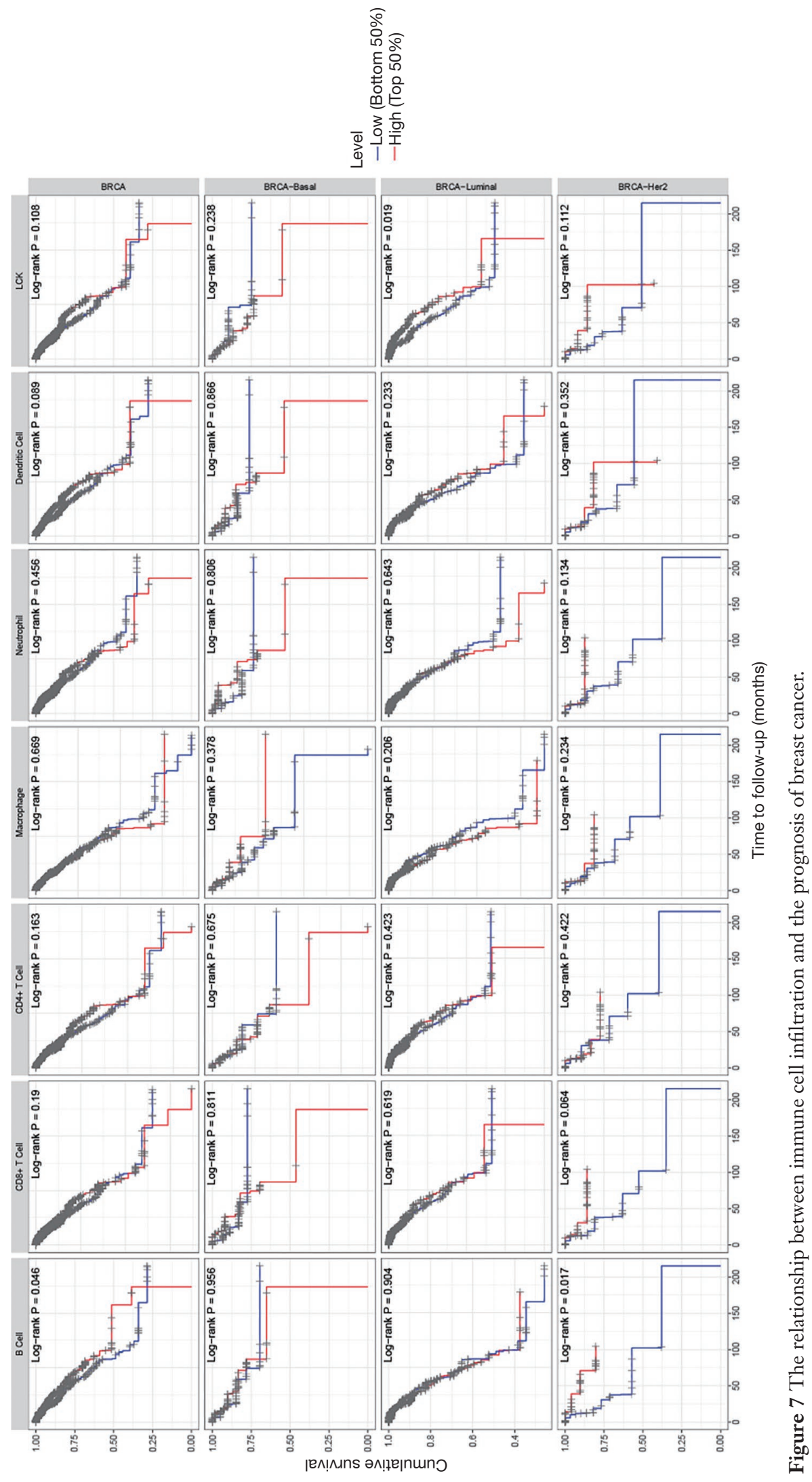


A

FDR $\leq 0.05 \quad F D R>0.05$

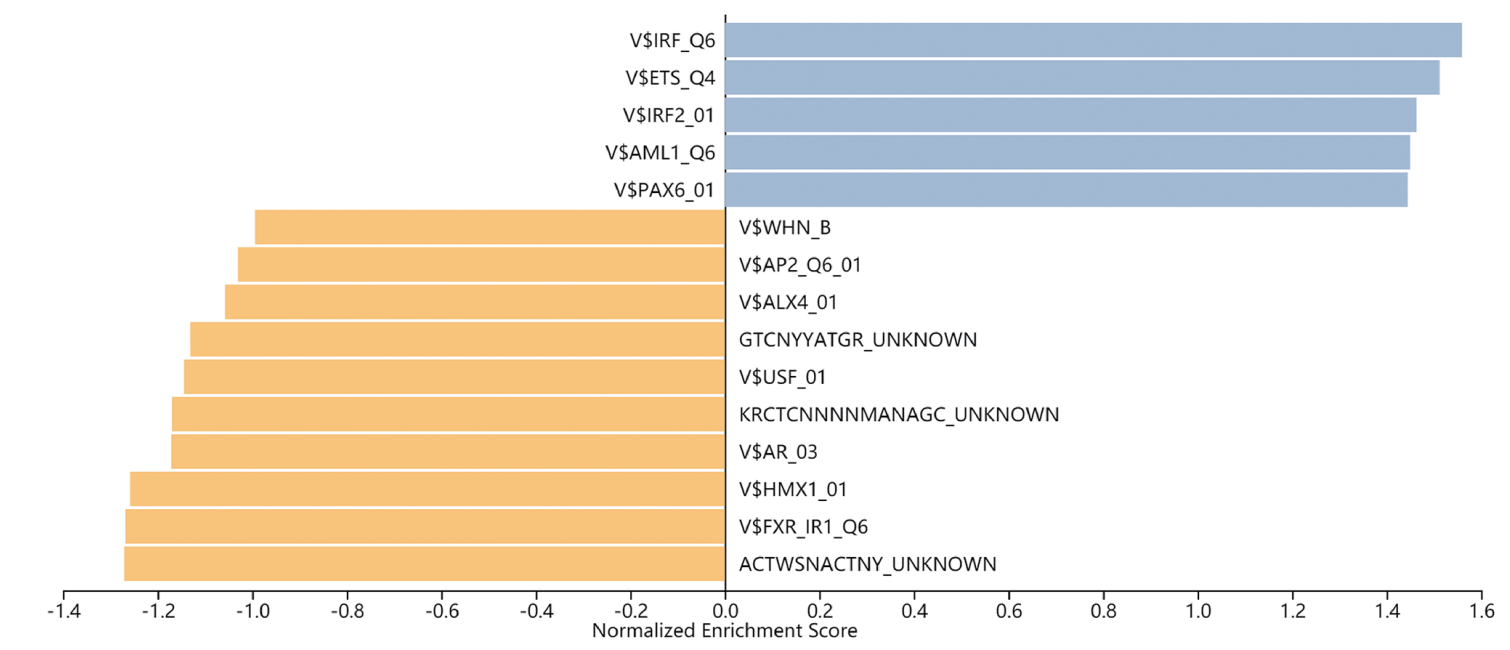

$\mathrm{B}=\mathrm{FDR} \leq 0.05 \square \mathrm{FDR}>0.05$

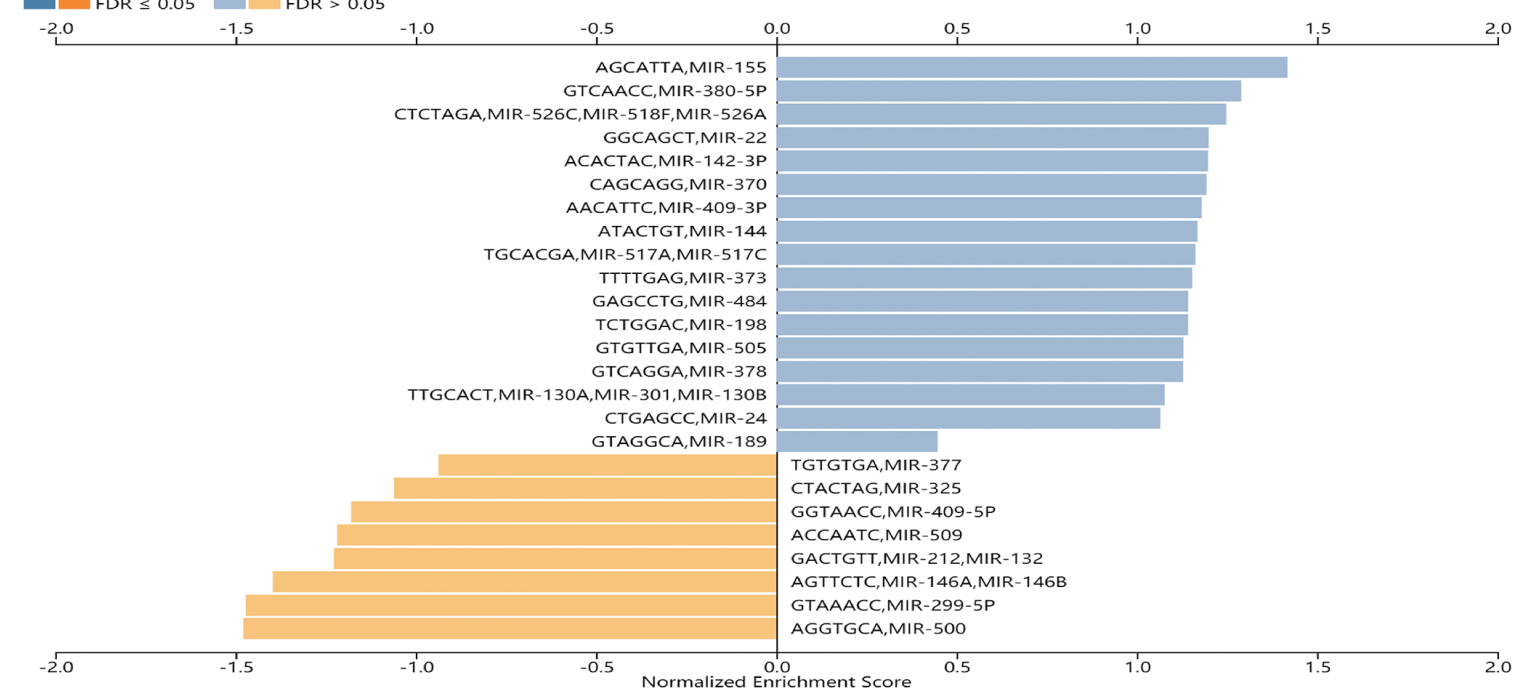

C FDR $\leq 0.05 \square$ FDR $>0.05$

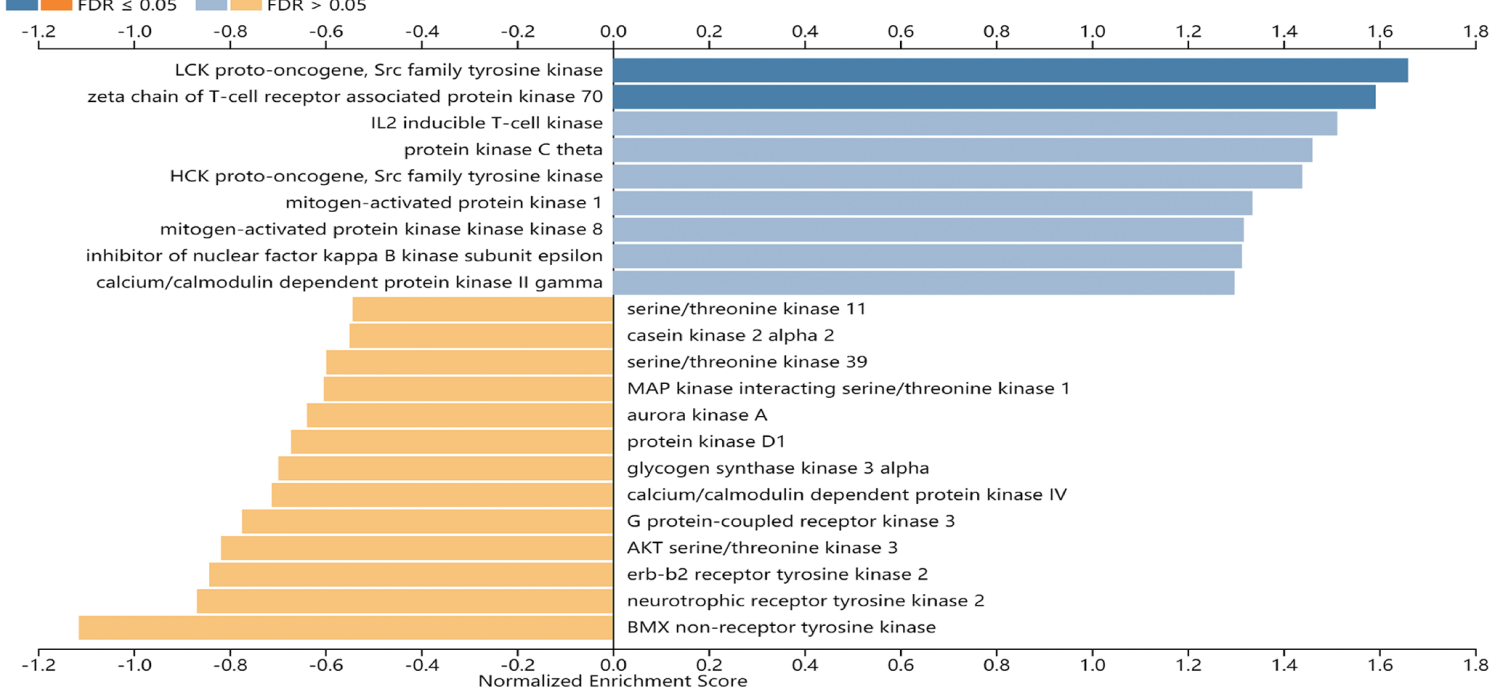

(C) Translational Cancer Research. All rights reserved. 
D $\quad F D R \leq 0.05 \square F D R>0.05$

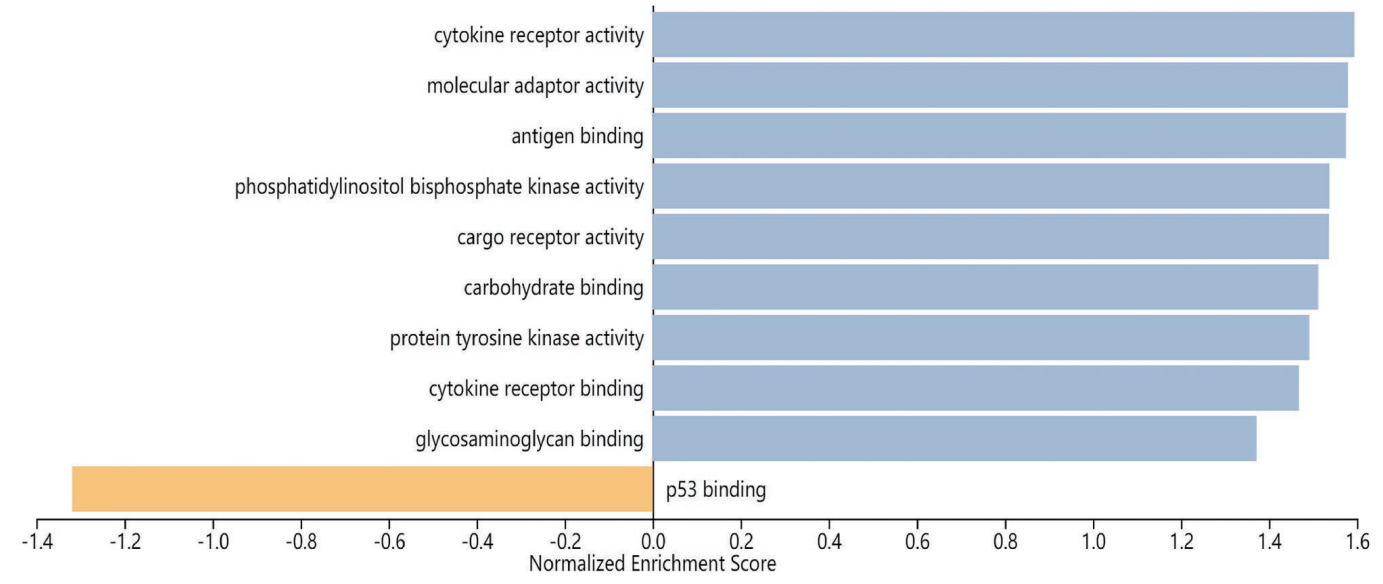

$E$

$F D R \leq 0.05 \quad F D R>0.05$

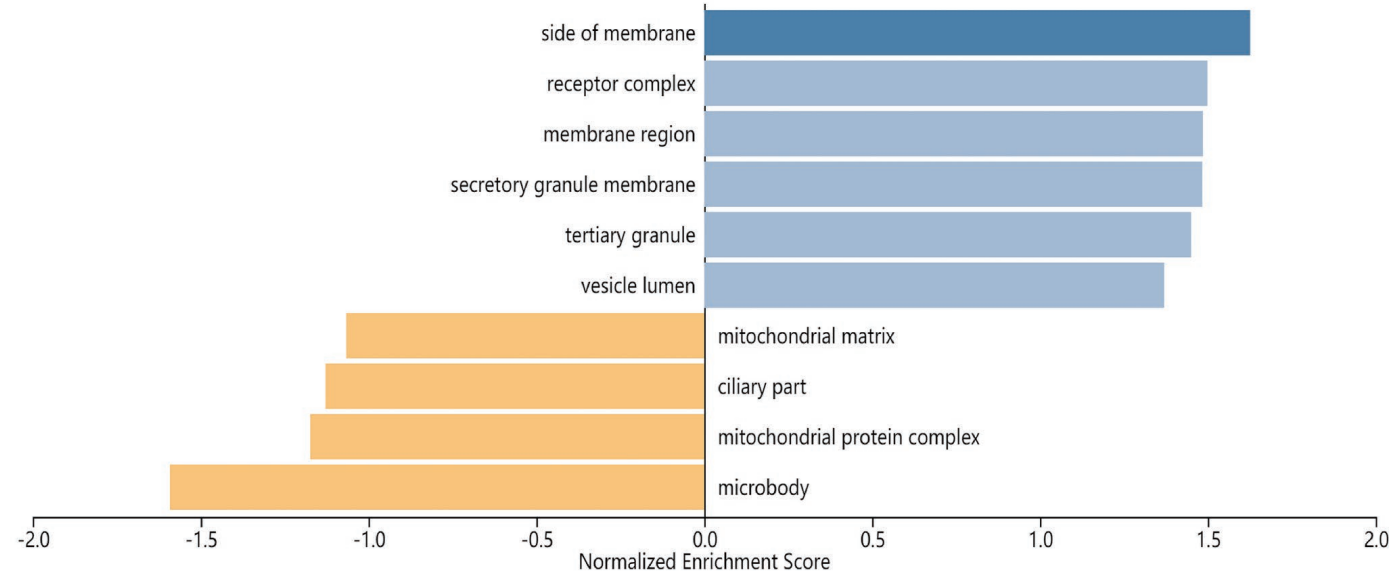

$\mathrm{F} \quad \mathrm{FDR} \leq 0.05 \square \mathrm{FDR}>0.05$

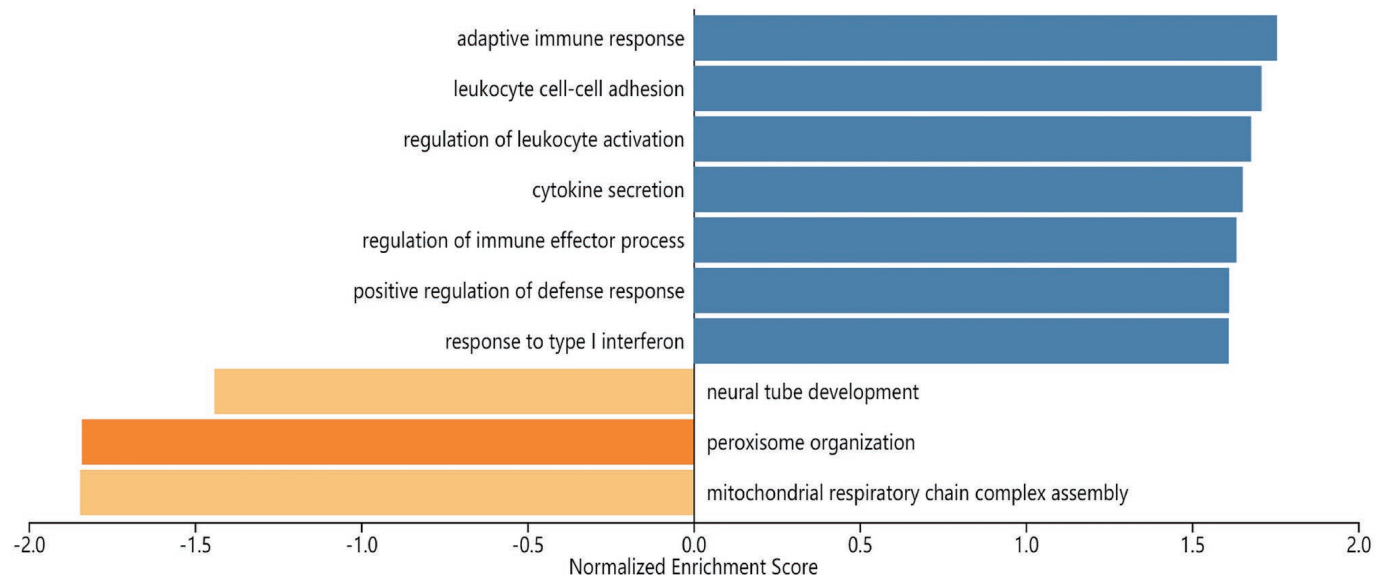

Figure 8 Functional enrichment analysis of LCK. (A) Enriched biological processes for LCK, (B) enriched cellular components for LCK, (C) enriched molecular functions for LCK, (D) kinase targets of LCK, (E) miRNA targets of LCK, and (F) transcription factor targets of LCK. LCK, lymphocyte-specific protein tyrosine kinase. 
Table 1 Kinase targets of differentially expressed glutathione peroxidases in LCK (LinkedOmics)

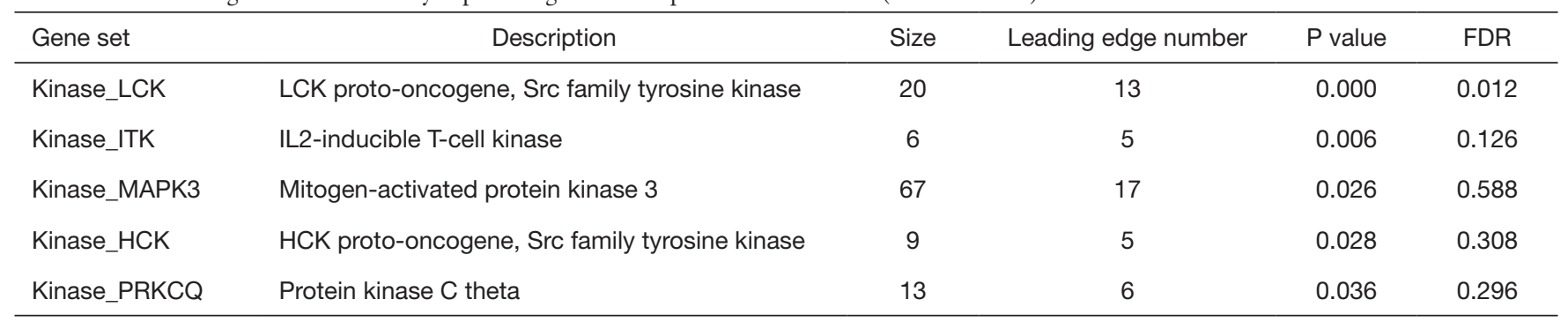

LCK, lymphocyte-specific protein tyrosine kinase.

Table 2 miRNA targets of differentially expressed glutathione peroxidases in BC (LinkedOmics)

\begin{tabular}{lcccc}
\hline Gene set & Size & Leading edge number & P value & FDR \\
\hline AGTCAGC, miR-345 & 22 & 6 & 0 & 0.11743 \\
CTITGTA, miR-524 & 117 & 31 & 0 & 0.15266 \\
CAGCCTC, miR-485-5P & 47 & 11 & 0 & 0.36502 \\
TITGCAG, miR-518A-2 & 66 & 12 & 0 & 0.53366 \\
AGGTGCA, miR-500 & 27 & 9 & 0.017857 & 0.23486 \\
AGCATTA, miR-155 & 46 & 13 & 0.031579 & 1 \\
\hline
\end{tabular}

$\mathrm{BC}$, breast cancer; Leading edge num, the number of leading edge genes.

155 as the 6 most significant miRNA targets of $L C K$ in BC. Also, a number of key TFs were found to have a regulatory association with the differential expression of $L C K$ in $\mathrm{BC}$ (Figure 9). Of note, AP1, SRF, and E2F1 were indicated to be key targets in the V\$IRF Q6, RYTTCCTG V\$ETS2B, and V\$RFX1 01 TF-target networks. Based on these results, it could be seen that there were many potentially significant regulators of LCK in BC.

\section{HPA analysis}

HPA was used to analyze the differences in the levels of LCK protein expression between normal and BC tissues. The results showed that LCK protein was overexpressed in $\mathrm{BC}$ as compared to normal tissue. An analysis of the significantly correlated genes for protein expression was also performed, and the results are shown in Figure 10.

\section{Discussion}

With the development of advanced diagnostic and therapeutic methods, the lifespan of patients with BC has been lengthened; yet, $\mathrm{BC}$ is still the biggest contributor to cancer-related deaths in women. Mechanistically, tumor formation, drug resistance, and immune response in $\mathrm{BC}$ are still poorly understood, which results in the poor management of patients with $\mathrm{BC}$. Therefore, more sensitive and specific novel biomarkers for the early diagnosis of BC are needed, as are novel therapeutic targets. It has been well established that aberrations in genes are important factors contributing to tumorigenesis, drug resistance, and tumor immunity. Various gene mutations have been reported in $\mathrm{BC}$, including $L C K$ mutation, which has also been found in other cancers. However, the fundamental biological functions of LCK in BC are still unexplored. In the current research, we comprehensively analyzed the expression levels and prognostic value of $L C K$ in $\mathrm{BC}$.

We found that LCK was significantly overexpressed in BC tissues compared to normal samples, and that overexpression of LCK is associated with an adverse prognosis in patients with BC. The expression of LCK may be influenced by age, histological subtype, co-mutation status, cancer status, and nodal metastasis. To date, few studies have reported on the expression of LCK in BC $(9,15,24)$, and the relationship between LCK expression levels and prognosis remains to be explored. Bai et al. revealed that LCK had a significant 


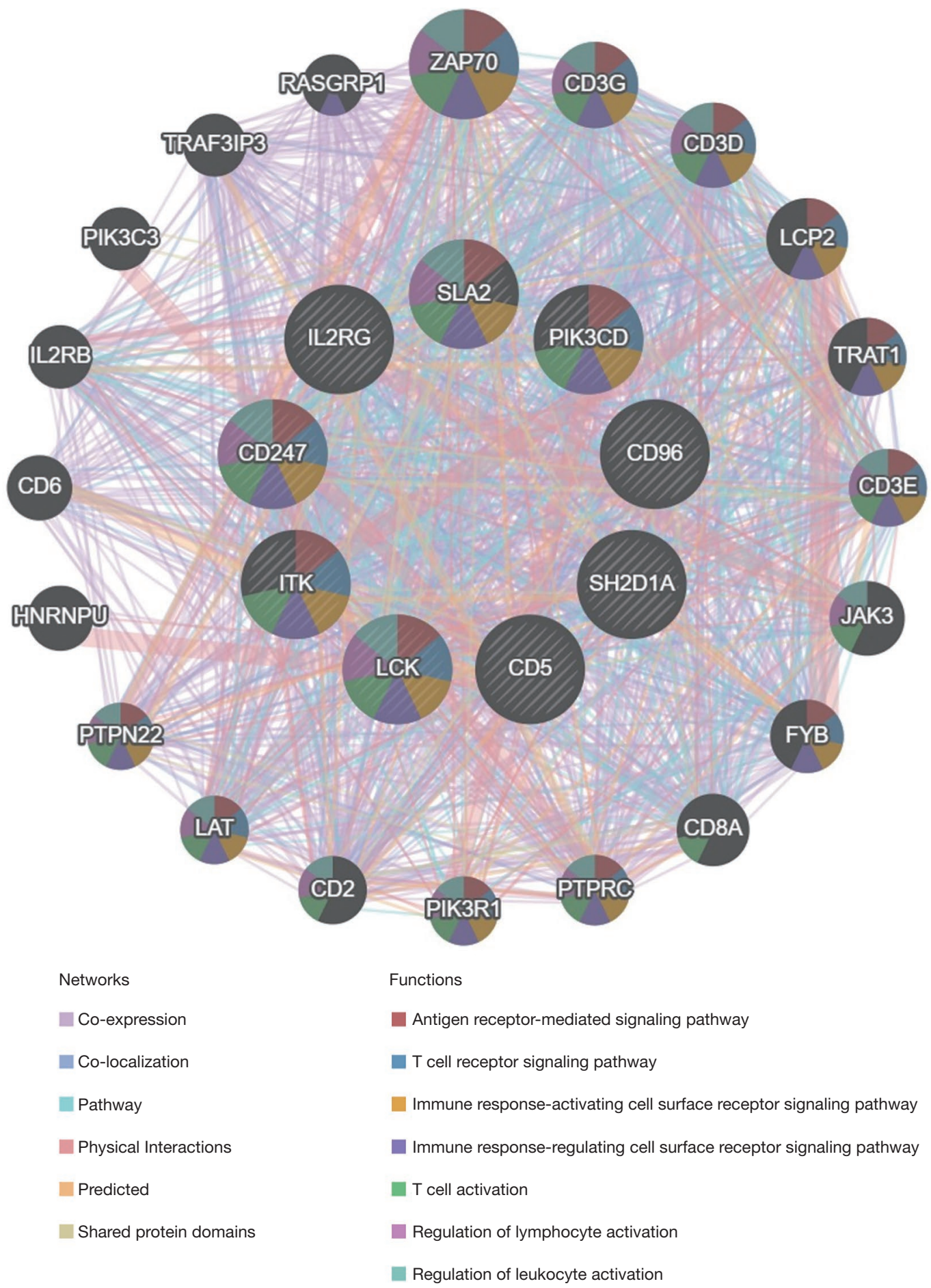

Figure 9 Protein-protein network of LCK and its significantly associated genes. LCK, lymphocyte-specific protein tyrosine kinase.

relationship with immune infiltration (15). Another study reported that LCK expression can act as a potential biomarker for predicting the recurrence of colon cancer (10).
Additionally, LCK expression has also been detected in lung cancer (24). There are several correlated significant genes of LCK that including CD5, CD96, CD247, IL2RG, 

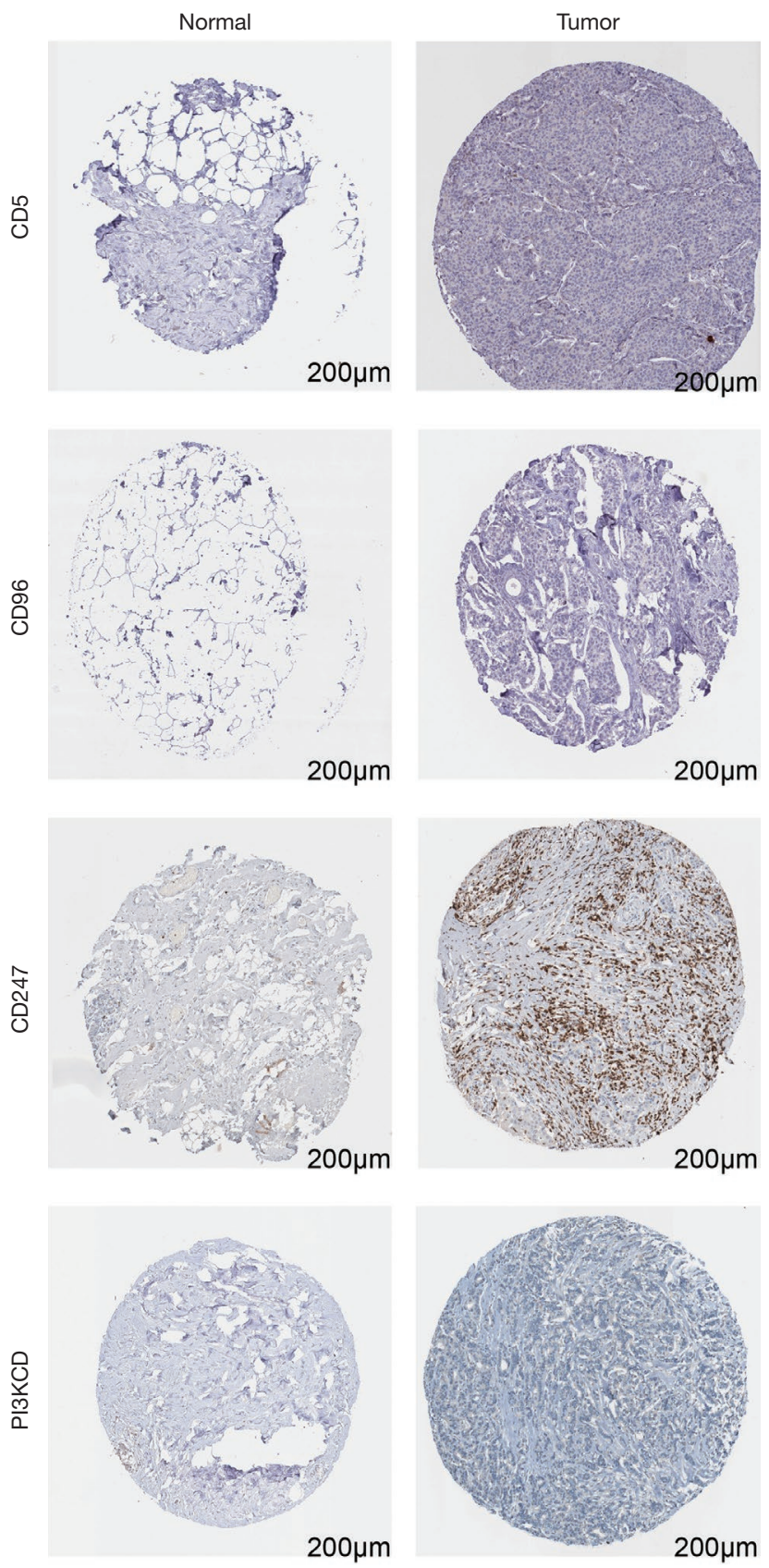

Figure $10 \mathrm{LCK}$ protein expression levels in samples of breast cancer tissue and normal breast tissue (HPA). LCK, lymphocytespecific protein tyrosine kinase; HPA, Human Protein Atlas.

ITK, PDCD1, PIK3CD, SH2D1A, and SLA2. CD5 has been observed to play a role in multiple types of lymphoma $(25,26)$, and it may act as a regulator of cancer immunity (27). Also, CD96 was detectable in hepatocellular carcinoma, and was shown to be involved in the prognosis of patients with the disease through its regulation of the fate of natural killer cells (28). Overexpression of CD96 has been indicated to be a positive biomarker of colorectal cancer (29). In one study on ovarian cancer, downregulation of CD247 was observed, and the gene was also found to affect patient prognosis through immune cell regulation (30). ITK has been shown to be a biomarker of malignant T-cell lymphoma, and its inhibition can induce tumor cell death via TCR signaling pathway inhibition (31). Another study showed that PIK3CD promoted the growth and invasiveness of colorectal cancer cells through AKT/GSK-3 $\beta / \beta$-catenin signaling activation (32). Moreover, PDCD1 also plays a role in immune regulation (33). However, no studies have been carried out to investigate the relationship between SLA2 and SH2D1A and cancer. All of this evidence hints that LCK and its associated genes play important roles in the pathogenesis of various cancers.

Despites of LCK was a regulator of T-cell receptor (TCR) signaling, the relationship between LCK and the tumor infiltrating lymphocytes (TIL) of BC did not have been explored. To investigate the biological functions of LCK, we performed a functional enrichment analysis of LCK in $\mathrm{BC}$, and the results showed that LCK plays roles in immune regulation, including in lymphocyte-mediated immunity, activation of natural killer cells, regulation of leukocyte activation, and regulation of viral defense. The tumor microenvironment plays a crucial role in cancer progression and therapeutic efficacy, and immune infiltrates are the major constituents of the microenvironment. In our study, we investigated the relationship between LCK and immune infiltration in multiple BC subtypes. We found infiltration by $\mathrm{B}$ cells, CD8+ T cells, CD4+ T cells, neutrophils, and dendritic cells to have a positive correlation with LCK, but LCK was negatively correlated with tumor purity. A previous study showed that LCK had a significant impact on immune infiltration in $\mathrm{BC}$, and that the overexpression of LCK was associated with a good prognosis (15). Thakur et al. revealed that patients with BC who had high levels of activated $\mathrm{T}$ cells had a longer time to progression than those who died not (34). Our current research revealed the following association of patient OS with immune infiltration in BC: the higher the level of tumor-infiltrating B-cells, the better the prognostic outcome. The study also highlighted the roles of other immune cells in BC.

Gene expression is regulated by various factors, including microRNAs and kinases. In our study, we found that there were several kinases [mitogen-activated protein kinase 3 (MAPK), HCK proto-oncogene, and protein kinase C 
(PKC) theta] and microRNAs (miR-345, miR-524, miR485-5P, miR-518A-2, miR-500, and miR-155) associated with the expression of LCK in BC. MAPK 3 is reported to be a promoter of tumorigenesis in AML. Numerous cellular functions, such as cell proliferation, differentiation, migration, and apoptosis, are regulated by MAPK pathways. Thus, aberrations of MAPK signaling pathway components play a central part in cancer development and progression (35), and aberrant MAPK3 activation has been observed in colorectal cancer (36). Also, in gastric cancer, overexpression of MAPK3 is associated with cisplatin resistance (37). Hematopoietic cell kinase (HCK), part of the cytoplasmic tyrosine kinase SRC family, can enhance the proliferation and survival of cells through physically associating with oncogenic fusion proteins and functionally interacting with receptor tyrosine kinases. Activation of HCK leads to colorectal cancer progression, and HCK is also observed in multiple myeloma and acute lymphoblastic leukemia $(35,38)$. The PKC family is divided into distinct protein classes with various cellular functions. When activated, PRKCQ can promote the growth ability of TNBC. Among the miRNA targets of LCK, miR-345-5p, miR-524, miR-485$5 \mathrm{p}$, and miR-518 act as tumor suppressors in certain cancers (39-42), and the overexpression of miR-155 was found to indicate drug resistance $(43,44)$. Various TFs associated with LCK have also been found in other cancer types $(45,46)$. The observations of the studies described above suggest an important role of LCK and its associated miRNAs and kinases in multiple cancers. In the present study, HPA analysis demonstrated that LCK and its correlated genes showed elevated expressions in BC samples as compared to normal breast samples. However, the limitation of this study is that absence of validation experiments.

\section{Conclusions}

In the present work, we performed a collective analysis of the expression and prognostic significance of LCK in $\mathrm{BC}$, and investigated the biological events related to the progression of $\mathrm{BC}$. The findings indicate that LCK is differentially expressed in $\mathrm{BC}$ and that its overexpression is linked to a poor survival outcome. Moreover, the results we obtained suggest that tumor immune status is an important factor for the prognostic outcomes of patients with BC, and that it could potentially serve as an indicator of prognosis in such patients. Regulatory network analysis of LCK showed its differential expression in $\mathrm{BC}$ to be implicated in immune cell regulation and activation, including lymphocytes, natural killer cells, and leukocytes, through a variety of tumor-related kinases (ITK and MAPK3), miRNAs (miR-345 and miR-524) and TFs (AP1, SRF, and E2F1), regulating cell proliferation, cell cycle progression, apoptosis, and survival. The limitations of the study include the small number of clinical samples and analysis using miRNA correlated genes. In future, functional validation should be performed to confirm the results obtained.

\section{Acknowledgments}

The authors would like to thank the Oncomine and LinkedOmics databases for providing open access to the LCK sequencing datasets.

Funding: This study was supported by funding from the National Natural Science Foundation of China (Grant No. 81372298 and 81572606).

\section{Footnote}

Reporting Checklist: The authors have completed the MDAR reporting checklist. Available at http://dx.doi.org/10.21037/ tcr-21-328

Conflicts of Interest: All authors have completed the ICMJE uniform disclosure form (available at http://dx.doi. org/10.21037/tcr-21-328). The authors have no conflicts of interest to declare.

Ethical Statement: The authors are accountable for all aspects of the work in ensuring that questions related to the accuracy or integrity of any part of the work are appropriately investigated and resolved. This study was approved by the Academic Committee of Guangdong Medical University and conducted according to the principles of the Helsinki Declaration (as revised in 2013).

Open Access Statement: This is an Open Access article distributed in accordance with the Creative Commons Attribution-NonCommercial-NoDerivs 4.0 International License (CC BY-NC-ND 4.0), which permits the noncommercial replication and distribution of the article with the strict proviso that no changes or edits are made and the original work is properly cited (including links to both the formal publication through the relevant DOI and the license). See: https://creativecommons.org/licenses/by-nc-nd/4.0/. 


\section{References}

1. Chen WQ, Zheng RS, Zhang SW, et al. Report of incidence and mortality in china cancer registries, 2008. Chin J Cancer Res 2012;24:171-80.

2. Zujewski JA, Dvaladze AL, Ilbawi A, et al. Knowledge Summaries for Comprehensive Breast Cancer Control. J Glob Oncol 2018;4:1-7.

3. Rojas K, Stuckey A. Breast Cancer Epidemiology and Risk Factors. Clin Obstet Gynecol 2016;59:651-72.

4. Salamanna F, Borsari V, Contartese D, et al. What Is the Role of Interleukins in Breast Cancer Bone Metastases? A Systematic Review of Preclinical and Clinical Evidence. Cancers (Basel) 2019;11:2018.

5. Voronova AF, Sefton BM. Expression of a new tyrosine protein kinase is stimulated by retrovirus promoter insertion. Nature 1986;319:682-5.

6. Ventimiglia LN, Alonso MA. The role of membrane rafts in Lck transport, regulation and signalling in T-cells. Biochem J 2013;454:169-79.

7. Bommhardt U, Schraven B, Simeoni L. Beyond TCR Signaling: Emerging Functions of Lck in Cancer and Immunotherapy. Int J Mol Sci 2019;20:3500.

8. Kim RK, Yoon CH, Hyun KH, et al. Role of lymphocytespecific protein tyrosine kinase (LCK) in the expansion of glioma-initiating cells by fractionated radiation. Biochem Biophys Res Commun 2010;402:631-6.

9. Wu T, Wang X, Li J, et al. Identification of Personalized Chemoresistance Genes in Subtypes of Basal-Like Breast Cancer Based on Functional Differences Using Pathway Analysis. PLoS One 2015;10:e0131183.

10. Clarke CN, Lee MS, Wei W, et al. Proteomic Features of Colorectal Cancer Identify Tumor Subtypes Independent of Oncogenic Mutations and Independently Predict Relapse-Free Survival. Ann Surg Oncol 2017;24:4051-8.

11. Rupniewska E, Roy R, Mauri FA, et al. Targeting autophagy sensitises lung cancer cells to Src family kinase inhibitors. Oncotarget 2018;9:27346-62.

12. Sugihara T, Werneburg NW, Hernandez MC, et al. YAP Tyrosine Phosphorylation and Nuclear Localization in Cholangiocarcinoma Cells Are Regulated by LCK and Independent of LATS Activity. Mol Cancer Res 2018;16:1556-67.

13. Saygin C, Wiechert A, Rao VS, et al. CD55 regulates selfrenewal and cisplatin resistance in endometrioid tumors. J Exp Med 2017;214:2715-32.

14. Zhao Y, Zhang X, Zhao Y, et al. Identification of potential therapeutic target genes, key miRNAs and mechanisms in acute myeloid leukemia based on bioinformatics analysis. Med Oncol 2015;32:152.

15. Bai F, Jin Y, Zhang P, et al. Bioinformatic profiling of prognosis-related genes in the breast cancer immune microenvironment. Aging (Albany NY) 2019;11:9328-47.

16. Tomczak K, Czerwińska P, Wiznerowicz M. The Cancer Genome Atlas (TCGA): an immeasurable source of knowledge. Contemp Oncol (Pozn) 2015;19:A68-77.

17. Chandrashekar DS, Bashel B, Balasubramanya SAH, et al. UALCAN: A Portal for Facilitating Tumor Subgroup Gene Expression and Survival Analyses. Neoplasia 2017;19:649-58.

18. Tang Z, Li C, Kang B, et al. GEPIA: a web server for cancer and normal gene expression profiling and interactive analyses. Nucleic Acids Res 2017;45:W98-W102.

19. Mizuno H, Kitada K, Nakai K, et al. PrognoScan: a new database for meta-analysis of the prognostic value of genes. BMC Med Genomics 2009;2:18.

20. Yang WS, SriRamaratnam R, Welsch ME, et al. Regulation of ferroptotic cancer cell death by GPX4. Cell 2014;156:317-31.

21. Vasaikar SV, Straub P, Wang J, et al. LinkedOmics: analyzing multi-omics data within and across 32 cancer types. Nucleic Acids Res 2018;46:D956-63.

22. Li T, Fan J, Wang B, et al. TIMER: A Web Server for Comprehensive Analysis of Tumor-Infiltrating Immune Cells. Cancer Res 2017;77:e108-10.

23. Uhlen M, Zhang C, Lee S, et al. A pathology atlas of the human cancer transcriptome. Science 2017;357:eaan2507.

24. Krystal GW, DeBerry CS, Linnekin D, et al. Lck associates with and is activated by Kit in a small cell lung cancer cell line: inhibition of SCF-mediated growth by the Src family kinase inhibitor PP1. Cancer Res 1998;58:4660-6.

25. Miyazaki K. CD5-positive DLBCL: molecular basis and treatment strategies. Rinsho Ketsueki 2015;56:1038-44.

26. Zhao P, Li L, Zhou S, et al. CD5 expression correlates with inferior survival and enhances the negative effect of p53 overexpression in diffuse large B-cell lymphoma. Hematol Oncol 2019;37:360-7.

27. Vasquez M, Simões I, Consuegra-Fernández M, et al. Exploiting scavenger receptors in cancer immunotherapy: Lessons from CD5 and SR-B1. Eur J Immunol 2017;47:1108-18.

28. Sun H, Huang Q, Huang M, et al. Human CD96 Correlates to Natural Killer Cell Exhaustion and Predicts the Prognosis of Human Hepatocellular Carcinoma. Hepatology 2019;70:168-83.

29. Song X, Tang T, Li C, et al. CBX8 and CD96 Are 
Important Prognostic Biomarkers of Colorectal Cancer. Med Sci Monit 2018;24:7820-7.

30. Ye W, Zhou Y, Xu B, et al. CD247 expression is associated with differentiation and classification in ovarian cancer. Medicine (Baltimore) 2019;98:e18407.

31. Liu Y, Wang X, Deng L, et al. ITK inhibition induced in vitro and in vivo anti-tumor activity through downregulating TCR signaling pathway in malignant T cell lymphoma. Cancer Cell Int 2019;19:32.

32. Chen JS, Huang JQ, Luo B, et al. PIK3CD induces cell growth and invasion by activating AKT/GSK-3 $\beta$ / $\beta$-catenin signaling in colorectal cancer. Cancer Sci 2019;110:997-1011.

33. Mishra A, Verma M. Epigenetic and Genetic Regulation of PDCD1 Gene in Cancer Immunology. Methods Mol Biol 2018;1856:247-54.

34. Thakur A, Rathore R, Kondadasula SV, et al. Immune T cells can transfer and boost anti-breast cancer immunity. Oncoimmunology 2018; 7:e1500672.

35. Pecquet C, Nyga R, Penard-Lacronique V, et al. The Src tyrosine kinase Hck is required for Tel-Abl- but not for Tel-Jak2-induced cell transformation. Oncogene 2007;26:1577-85.

36. Byerly J, Halstead-Nussloch G, Ito K, et al. PRKCQ promotes oncogenic growth and anoikis resistance of a subset of triple-negative breast cancer cells. Breast Cancer Res 2016;18:95.

37. Cao HY, Xiao CH, Lu HJ, et al. MiR-129 reduces CDDP resistance in gastric cancer cells by inhibiting MAPK3. Eur Rev Med Pharmacol Sci 2019;23:6478-85.

38. Podar K, Mostoslavsky G, Sattler M, et al. Critical role for hematopoietic cell kinase (Hck)-mediated phosphorylation

Cite this article as: Meng Y, Huang T, Chen X, Lu Y. A comprehensive analysis of the expression and regulation network of lymphocyte-specific protein tyrosine kinase in breast cancer. Transl Cancer Res 2021;10(3):1519-1536. doi: 10.21037/ tcr-21-328 of Gab1 and Gab2 docking proteins in interleukin 6 -induced proliferation and survival of multiple myeloma cells. J Biol Chem 2004;279:21658-65.

39. Feng C, Xian Q, Liu S. Micro RNA-518 inhibits gastric cancer cell growth by inducing apoptosis via targeting MDM2. Biomed Pharmacother 2018;97:1595-602.

40. Wang M, Cai WR, Meng R, et al. miR-485-5p suppresses breast cancer progression and chemosensitivity by targeting survivin. Biochem Biophys Res Commun 2018;501:48-54.

41. Zhen Z, Dong F, Shen H, et al. MiR-524 inhibits cell proliferation and induces cell apoptosis in thyroid cancer via targeting SPAG9. Eur Rev Med Pharmacol Sci 2018;22:3812-8.

42. Mou T, Xie F, Zhong P, et al. MiR-345-5p functions as a tumor suppressor in pancreatic cancer by directly targeting CCL8. Biomed Pharmacother 2019;111:891-900.

43. Merchant PC, Godse CS, Varthakavi PK, et al. Prevalence of islet cell antibodies and B cell functional status in insulin dependent diabetes. J Assoc Physicians India 1996;44:457-60.

44. Santos JC, Lima NDS, Sarian LO, et al. Exosomemediated breast cancer chemoresistance via miR-155 transfer. Sci Rep 2018;8:829.

45. Qiao J, Liu Z, Yang C, et al. SRF promotes gastric cancer metastasis through stromal fibroblasts in an SDF1CXCR4-dependent manner. Oncotarget 2016;7:46088-99.

46. Enjoji S, Yabe R, Tsuji S, et al. Stemness Is Enhanced in Gastric Cancer by a SET/PP2A/E2F1 Axis. Mol Cancer Res 2018;16:554-63.

(English Language Editor: J. Reynolds) 